\title{
Erratum to: Oxidative Stress Biomarkers in Some Rat Brain Structures and Peripheral Organs Underwent Cocaine
}

\author{
Lucyna Pomierny-Chamioło • Andrzej Moniczewski • \\ Karolina Wydra $\cdot$ Agata Suder $\cdot$ Małgorzata Filip
}

Published online: 10 August 2012

(C) Springer Science+Business Media, LLC 2012

\section{Erratum to: Neurotox Res}

DOI 10.1007/s12640-012-9335-6

The original publication of the article contained wrong data in Fig. 1; the correct graphs showing the mean number of

responses in active and inactive levers for rats that acquired self-administration of cocaine and their yoked controls that received passive infusions of cocaine or saline are as follows:

The authors sincerely apologize for these errors.

The online version of the original article can be found under doi:10.1007/s12640-012-9335-6.

L. Pomierny-Chamioło $(\bowtie) \cdot$ A. Moniczewski · M. Filip Department of Toxicology, Faculty of Pharmacy,

Medical College, Jagiellonian University, Medyczna 9, 30-688 Kraków, Poland

e-mail: lpomiern@cm-uj.krakow.pl

K. Wydra · A. Suder · M. Filip

Laboratory of Drug Addiction Pharmacology, Department of Pharmacology, Institute of Pharmacology, Polish Academy

of Sciences, Smętna 12, 31-343 Kraków, Poland 

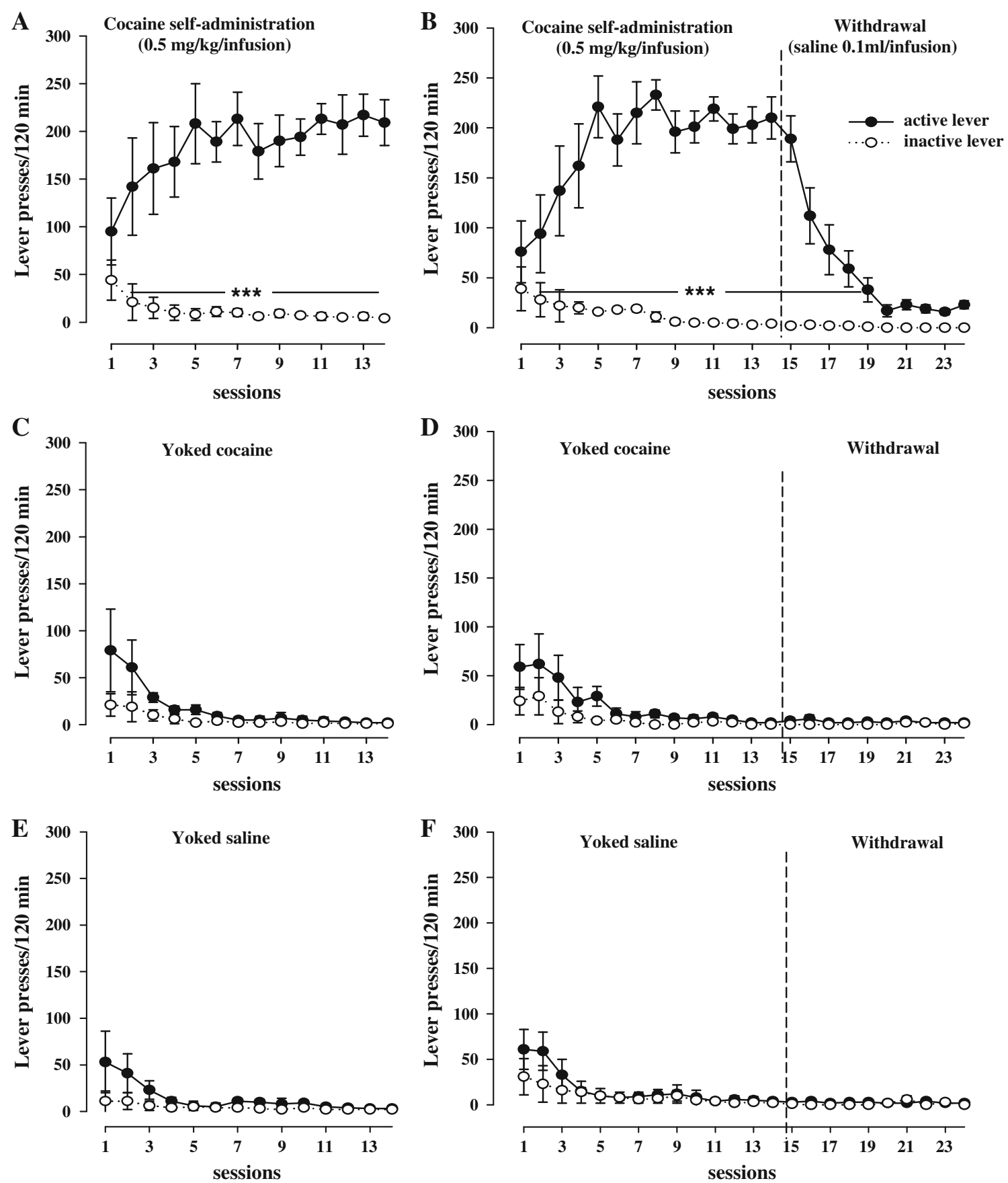

Fig. 1 The mean number $( \pm$ SEM $)$ of responses in active and inactivelevers for rats that acquired self-administration of cocaine at a dose of 0.5 $\mathrm{mg} / \mathrm{kg} / \mathrm{injection}$ and their yoked controls that received passiveinfusions of cocaine or saline. ${ }^{*} p<0.001$ versus inactive lever. $N=6-8$ rats/group 